\title{
Diversified Performance of Floury Flower under the New Situation
}

\author{
Weina Sheng \\ Weinan Normal University, Weinan, Shaanxi, 714000, China
}

Keywords: Floury Flower Art, Diversify, New Floury Flower

\begin{abstract}
For the purpose of carrying forward the art of floury flower, this article elaborated the diversified performance of floury flower under the new situation from three aspects: the necessity of diversified performance of floury flower, the diverse manifestations of floury flower, and the diversify development of floury flower.
\end{abstract}

\section{Introduction}

Face flower as a national cultural resources rooted in folk soil, embodies the rich human design ideas, but the inheritance of folk art is not static, but as the times continue to grow, flower art at different levels, multi-angle Re-understanding, and then explore the inevitable result of social development. If you want to make progress, you must show individuality."

\section{A Variety of Face Flower Art}

With the continuous development of research on the social overall culture and the theory of art, the concept of modern culture tends to develop in a multi-dimensional manner. With the continuous updating of modern science and technology, the aesthetic appreciation of human flower art is constantly being enriched. Art of flour flower as a symbol of folk culture, Is a beautiful folk culture landscape. However, due to the impact of the social transformation in China, the living environment is deteriorating. As one of the intangible cultural heritage inherited through oral tradition, it is rapidly disappearing. Face flower, as one of the intangible cultural heritage in China, is not optimistic Inheritance of innovation, multi-style inheritance is a new way of flower art.

The new face flower is a novel art form relative to the original face flower. Through the intervention of modern elements such as the electronic medium and the paper medium, the modern art expands the application fields of the traditional face flower and makes use of the modern technology to the face flower Innovative practice, so that the original ecological culture affects the modern culture, but also allows the modern into the original ecology, so that Mianhua art in the inheritance of the development and inheritance, innovation and breakthroughs.

In short, no matter what kind of art is presented, all have their own independent visual psychological foundation. As the perception of art is transformed into artistic reproduction The process of human visual and non-visual factors are very important, that is, by the admirer and creator to reflect the integrity of the artwork. Face flower art appreciation and creator in a multi-cultural development of a new generation, this feature determines that we have to face the flower of the deep level of mining, development and utilization, the only face flower art can continue to gain popular support, Get good development.

\section{Face Flower Variety Show}

Culture is pluralistic and its expression is varied:

\subsection{The traditional face flower presentation}

Traditional surface flowers are made of noodles as the main material made of folk art, known as the "flowers", "flower bread", originated in the folk sacrifice activities with plastic animals instead of slaughtering animals such as cattle and sheep customs, applied to the wedding, life, full moon, 
sacrificial offerings and other folk activities, both to eat the practicality, but also watch the ornamental, popular in China to eat pasta-based North [1].

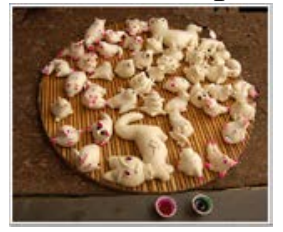

Figure 1 traditional face flower

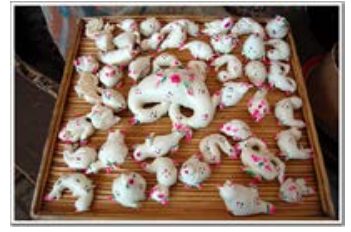

Figure 2 traditional face flower

Traditional surface flowers are mainly made of flour, water and food coloring and some beans, peanuts, dates, walnuts, peppers, paper and other auxiliary materials, making tools mainly from the basin, toothpicks, combs, scissors, needles and other daily necessities. Production points is to make full use of combs, scissors and other tools, through the comb pressure, scissors, hand pinch and other methods made. For example, using scissors to cut out beautiful graphics, such as fish scales, chicken body hair, with comb out of some patterns such as: fins, hand pinch out some flowers and other decorations, through the use of toothpicks will do The fragmented shape and the main body to connect. Finally, the use of pigment, or beans, peanuts, dates, walnuts, peppers and other points, line elements are for decoration, modeling novel, rich colors. It has appeared in the commodity market, resulting in economic benefits.

The traditional surface of the main points are edible and inedible two edible surface flowers are the usual gift face flowers, the use of natural pigment, made of flour can be eaten, but the color is not very bright. Incombustible surface flower is mainly participating flower, due to the use of chemical dyes, although the face flower color made brilliant, but inedible, can only watch.

\subsection{Face flower paper presented}

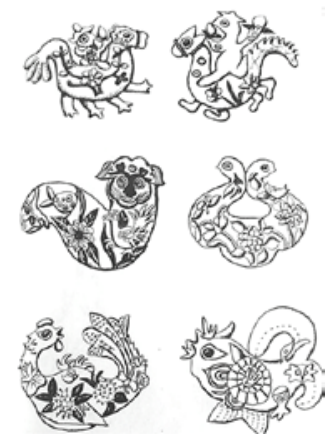

Figure 3 Paper face flower pattern

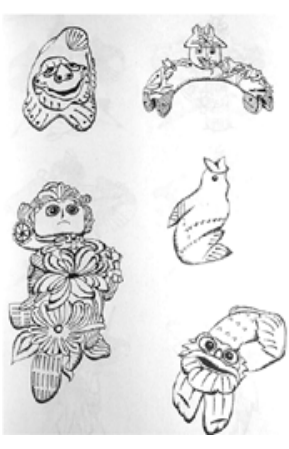

Figure 4 Paper face flower pattern

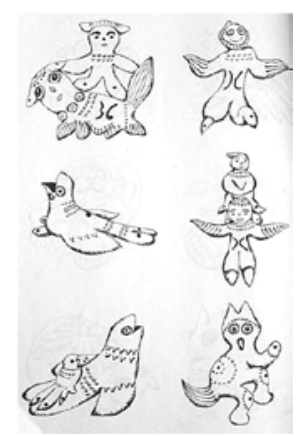

Figure 5 Paper face flower pattern

Paper surface flower [2] is based on the paper as a carrier surface pattern recording and face flower design, the advantage is easy to manage and use.

Paper records relative electronic records more arbitrary, has become a lot of artists to collect inspiration. Simon Dunant, a creative industry man, likes to graffiti and record the world in his eyes anytime, anywhere: "I do not like environments that are too regulated. Many of them are inspired by divergent thinking when they feel free, Paper records with randomness, this is a breeding ground 
for inspiration. I often in my own work, diary easy to record the feelings of thought, sometimes words, sometimes sketches, these are my precious wealth, because They bring a lot of good advertising ideas to me. "As a successor to Art Nouveau, paper recording or creation is also essential, and the existence of paper noumenon also requires our deep thinking and the study.

\subsection{Face flower digital presentation}

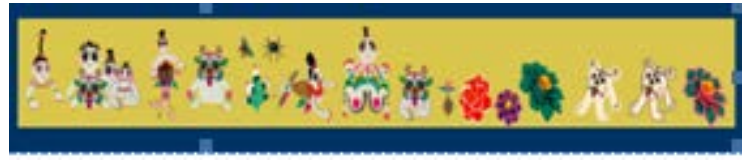

Figure 6 digital face flower picture

The advent of the digital age, the intervention of modern elements, the transformation of various traditional mediums into electronic mediums, and the extension of modern technologies to the usual fields of application. Digitizing surface flowers came into being based on the excavation and study of traditional surface flowers. Digital face flower is a novel art form relative to the original face flower. It has some inheritance relationship with folk face flower. It is a combination of original culture and modern culture, and a combination of technology and art. Through the digital research on the flower art of the opposite side, we grasp the profound connotation of the Chinese culture and the Chinese aesthetic spirit, and at the same time conform to the social development, innovate the flower art and expand the influence of flower art, and promote the modern Design work expressiveness. Digital face flower making convenient, can be modified at any time, with the combination of modern multimedia technology, the face flower art and other multi-door art combined with digital facial flower animation, digital face flower pattern design and other new styles, effectively expanding the face Flower art applications and spread of the scope, face flower art business value has been improved. The digital face flower combined with digital technology is conducive to displaying, collecting, using, exploring, discovering, creating, reorganizing, summarizing and evaluating opposite flower resources. Innovative practices that can be applied to flowers across the board from modern technology: art creation activities such as digitized flower design, digital face flower graphic design and digital face flower animation design.

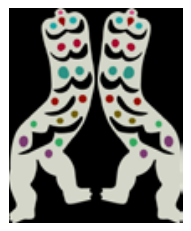

Figure 7 digital face flower pattern

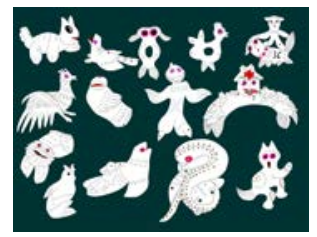

Figure 9 digital face flower components

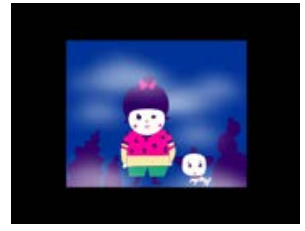

Figure 11 digital flower animation screenshot

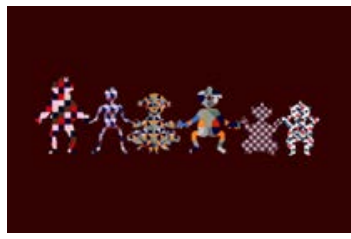

Figure 8 digital face flower plane design

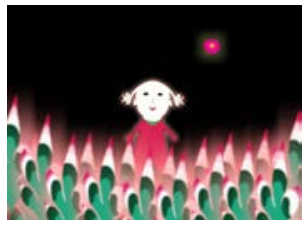

Figure 10 digital flower animation screenshot

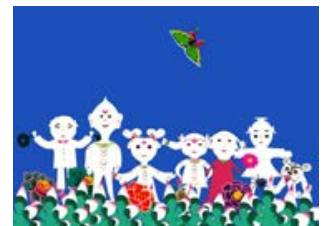

Figure 12 digital flower animation screenshot

\subsection{Other media face flower}

The same content due to different media, resulting in different content production and editing logic, different market needs, different business models, and therefore in the multi-cultural and 
diverse needs of today, face flower art is not just the traditional face to face as the main The physical display of materials, paper displays, electronic displays, and the display of other kinds of new materials have become inevitable in the past. The combination of art, such as pottery, clay sculpture, anime, and face flower art will enhance the charm of face flower art. For example: the combination of modern animation can be derived from a variety of texture face flower shape cartoon toys.

\section{The Development of Face Flower Art}

During the teaching of face flower art, it makes deep researches and researches on the face flower art modeling research, aesthetic culture research, that is, the modeling concept, aesthetic standard and aesthetic ideal of the opposite flower art. Opposite the theme of flower art, modeling, color, performance, as well as commercial innovation research. Such as the concept of the original shape of the flower pattern and the original pattern of the original flower pattern, and then the sensory rendering of the image, the symbolic communication of meaning and the vivid artistic conception of artistic conception are discussed respectively. On the basis of digital technology, combining with the creative thinking of the traditional flourishing color system, we started to innovate the flourishes and create a new color system based on the concept of color system of concept of life and birth, yin and yang and five elements of gossip in Chinese traditional folk art [3] The new color system of the times. Second, we can also combine face flower art with paper cutting, shadow play, embroidery, mask and other ethnic arts, or combine face flower, Q facial expression, animation style, illustrator and other modern art to recreate face flower art.
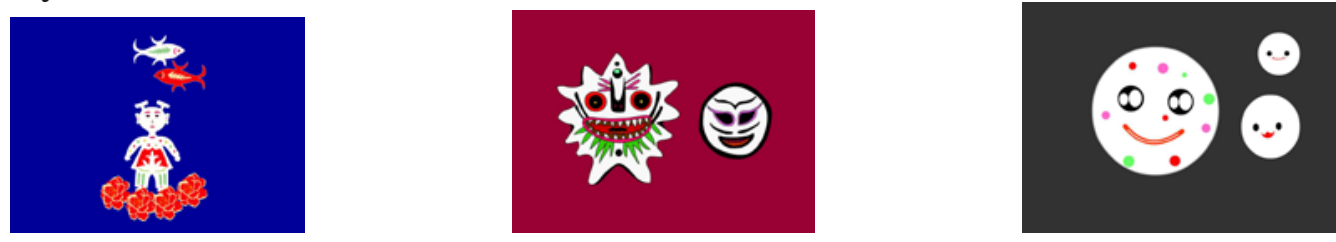

Figure 13 combination of flower and paper-cut Figure 14 combination of flower and mask Figure

15 face flower and the combination of Q expression
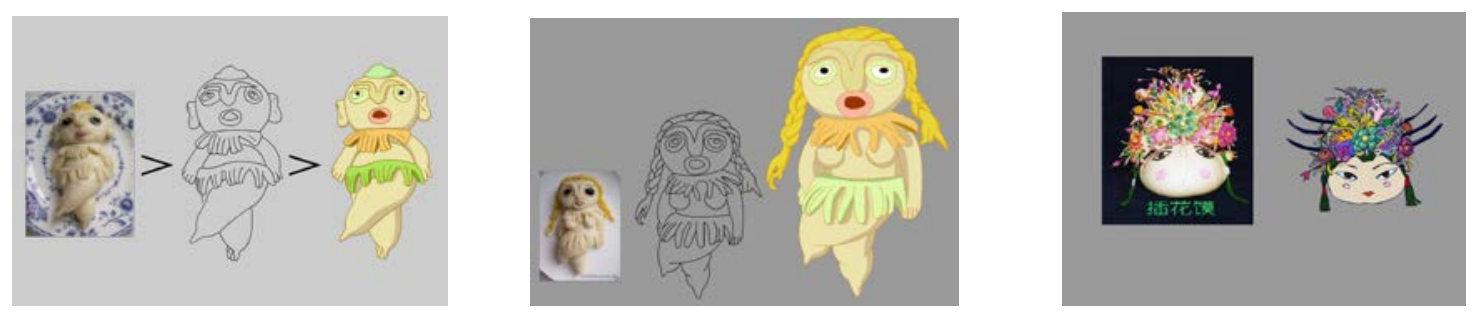

Figure 16 knot flowers and animation style knot Figure 17 face flower and illustration of the combination

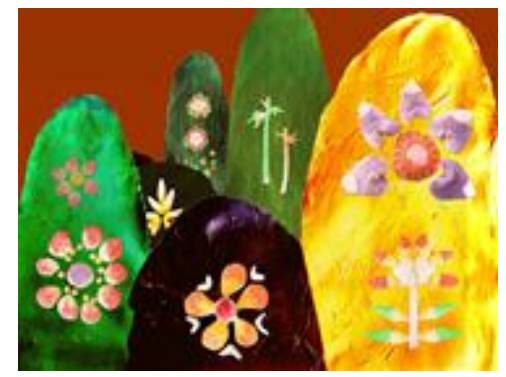

Figure 18 Combination of face flowers and animation

Not only the general art itself, but also the arts related to science, humanities and technology, such as the common development of science and technology, humanities and arts, sensory arts, life art and entertainment art. Each creation objectively accumulates culture. The creation of cultural and cultural creation activities through creation requires the carrying out of various forms of social 
practice. This requires us to carry out interactive development of flower-faced arts. We can make use of modern technology to innovate and practice the flower of the opposite side and mix other traditional art elements in the face flower art so as to produce the flower animation art, the face flower digital pattern design and the face flower installation art. It has inherited folk traditional culture by means of "creation" and given new life and vitality to traditional culture.

In short, through the in-depth analysis and study of the diversity of flower art, it not only conforms to the social development, but also innovates the flower art, expands the influence of flower art, expands our creative thinking and promotes the modern design work Expressive. At the same time, in the process of carrying on the diversified traditions of flower art, it is necessary to not only inherit "artistry" but also inherit "spirit", that is, the cultural feelings of the nation. We must also let young students into folk culture, enjoy folk culture, love folk culture, our folk culture can get a good heritage and development.

\section{References}

[1] Lu Zhongmin. Do face flower. External communication, 2003, (01)

[2] An Zhongzhong "Atlas of Folk Art" [M]. Shaanxi People's Fine Arts Publishing House, 1996.12, p. 158

[3] Jin Zhilin. "Chinese folk art" [M] Beijing: Wuzhou Press, 2004.8, p.64 